\title{
The Present Situation and Countermeasures of the Integration of Traditional Culture into Ideological and Political Education in Colleges and Universities
}

\author{
Zhi-quan $A n^{1, a}$, Kai Wang ${ }^{1, b,{ }^{*}}$, Peng Iv $v^{1, c}$ \\ ${ }^{1}$ Beihua University, Jilin, China \\ ${ }^{*}$ Corresponding author
}

Keywords: traditional culture; ideological and political education

\begin{abstract}
In the present society, the influence of excellent traditional Chinese culture is not enough, and the ideological and political education of college students is facing various difficulties, need of urgent innovation. In the ideological and political education in colleges and universities, we should pay attention to students' actual situation, appropriately blend traditional Chinese culture in, and focus on its impact on life, the integration of the two will be placed in the student's life to form an organic integration and natural combination. Faced with many problems in the process of integration, we should create an ideal academic environment through the unique characteristics of moral education in colleges and universities, so as to promote the integration of excellent traditional Chinese culture and ideological and political education.
\end{abstract}

At present, with the continuous development of economic globalization and the market economy as well as the transformation of the popularization of higher education in China, college students' ideological activities of "independence, selectivity, variability, dissimilarity" are outstanding, value concept appears a diversified development trend, the influence on students under the western social values gradually increases, while the excellent traditional culture deposits are undergoing a serious lack of heritage. Therefore, to strengthen the excellent traditional culture education of college students has a strong urgency and severity.

\section{The present situation of Chinese traditional culture education}

(a)The decline of traditional Chinese culture

Cultural Division. The excellent traditional Chinese culture is currently in unprecedented decline, since modern times, the big powers of had waged wars of aggression against China, coupled with the domestic melee, civil wars and the cultural revolution and other mistakes, which led the traditional Chinese culture to a phenomenon of serious division. It is said that only when food and clothing are adequate can etiquette be achieved, due to the long war and poverty, it is difficult for people to experience cultural activities. Coupled with the low national education rate led by poverty and wars, as everyone knows culture takes education as an important carrier of communication, in this environment, culture division was almost inevitable, many forms of culture disappeared and many principles of conduct were abandoned are important reasons for the decline of the traditional Chinese culture, and they are also the important problems we need to solve when it is integrated into the ideological and political education.

Culture dilution and alienation. At present, the world is developing rapidly, and the breakthrough of information technology has made the earth a global village, which promotes the exchange between the countries of the world, but this communication also leads to the dilution and alienation of traditional Chinese culture. This phenomenon is particularly prominent among teenagers, and college students are an important part of this group. And surveys show that for contemporary college students, the important form of culture -- festivals. The current pace of social life is faster, many forms of Chinese traditional festivals are more complicated, and most of them give people the image of "unfashionable", then it is difficult to cause the interest of young college students with pursuit of fashion. In fact, this non-identity is a culture and thought penetration to 
young people by European and American countries at the era of information explosion. Chinese traditional festivals for college students have nothing less than eating, or they just imitate foreign festivals, many college students with a higher level of knowledge and technology are yearning for the culture of other countries. However, the dilution and alienation of traditional Chinese culture has weakened its influence on college students, which will be the important problems we need to solve when it is integrated into the ideological and political education

(b) There are obstacles in college students' acceptation

Information saturation. Due to the breakthrough of social communication technology in current society, it lead to extreme expansion in information. College students will absorb a large amount of information in daily life, among which a large part is spam, so the students in the current situation are receiving information with a saturated state, it's difficult to have more energy to receive the complicated knowledge of traditional culture. In fact, this information saturation reflects in many ways. First, the information itself has a large amount intermingled with the good and bad, the excellent traditional Chinese culture is just part of it, and in this complex information, to find the excellent traditional culture and to well understand and learn it has a demand of certain understanding of the traditional culture, this is the death cycle of chicken and egg problem. Secondly, the current flow of information is too fast, on information understanding people only stay in the "know" level, after the students' receiving huge surface information, the impetuous phenomenon will naturally emerge, it is not conducive for traditional Chinese culture to play its role effectively which causes the restriction in promoting the ideological and political education.

Lack of interest. Compared to the society of past 80 years , there is a wealth of entertainment in today's society, a variety of electronic products continuously emerge to attract people, television programs are becoming more and more close to the audience's preferences, while compared with the entertainments, Chinese culture becomes a bit boring. Actually, this so-called boringness has noting to do with its unattractiveness, otherwise it will not stand for thousands of years without falling. This boringness is actually from the impetuous environment, the excellent traditional Chinese culture need us to deeply know it, so as to extract the endless fun from it, but this process of understanding clearly makes people uninterested. As is known to all, the ideological and political education itself has long been regarded as a boring label because of its characteristics. When these two kinds of "boring" things are fused together, it is difficult to stimulate the enthusiasm of students.

External and internal forces. In today's society, the culture shock European and American countries as well as Japan and South Korea taken to China is extremely serious, actually the developed countries, in the current world situation, are waging cultural invasions to other countries every hour and moment, among Chinese young people with college students as the typical ones, many are very interested in the cultures of other countries. In turn, in the face of the traditional Chinese culture, it was generally named superstition and lagging behind, this phenomenon makes people's sense of identity decline. Compared with other subjects, ideological and political education has different teaching aims with correcting and changing people's ideas, it has long been disliked by a lot of people, added that people who have an ulterior motive may conduct malicious slander, making people produce inimical mood towards it. This phenomenon has gone far without easy return, so in fact the excellent traditional Chinese culture and the ideological and political education are facing the same problem.

\section{Countermeasures for the integration of the excellent traditional Chinese culture into the ideological and political education}

(a) Strengthen the excellent Chinese culture through ideological and political education Vigorously strengthen the inheritance of the essence of excellent Chinese culture. In the face of culture division, in fact the strength educators can contribute to culture is limited, the filling of it needs more professional and knowledgeable people to conduct in-depth research for the restoration, for the ideological and political education, its essence is to achieve its goal of education, the fusion of traditional Chinese culture through the identity of national culture is mainly to realize their own 
teaching efficiency as well as to promote the all-round development of people, and achieve the great rejuvenation of the Chinese culture. "To strengthen the education of the excellent traditional Chinese culture and develop and utilize the rich resources of national culture by means of modern science and technology."

Strengthen the status of the excellent traditional Chinese culture and correct the alienation. As institutions of higher learning, universities should have enough sense of social responsibility, no matter what the society shows, as a school, it is necessary to create a strong cultural atmosphere. In such a strong cultural atmosphere, students can really identify with their own culture, so as to achieve intimate terms with the traditional Chinese culture from ideological and political lessons, and to achieve the purpose of improving the efficiency and quality of teaching. The specific methods are such as pasting marked banners around schools with the cultural characteristics, seting up student associations with the excellent traditional Chinese culture as the core, and organizing cultural and sport activities, etc. Through the support of the school, increase the influence of the early stage, and supervise its activities. So as to form a subtle influence on students outside the classroom. The form of influences government and culture have on people also achieves the purpose of ideological and political education, and even forms he advanced teaching methods of the ideological and political education affecting people in life. As for the cultural phenomenon of alienation, it should be corrected by the knowledgeable through the efforts of all parties, and appropriate activities should be organized to let the students participate in to deeply feel, so as to wipe out cultural alienation traces from the hearts of students.

\section{(b) Ease students' information saturation}

In order to alleviate the saturation of information, we should start from two aspects. Firstly, we should explicitly put the traditional Chinese culture in the ideological and political education to make the students understand clearly and cognize correctly. Compared to the way of concealing traditional Chinese culture into the ideological and political education, this will not be clever, but to be clear and plain is the most appropriate way, because students' understanding basis of traditional culture is weak, the clear and obvious of "combination" can achieve the most intuitive results, and has strong resistance to information saturation. Secondly, give a man a fish and you will feed him for a day, but teach him how to fish you will feed him for a lifetime, in the process of ideological and political education, if the similar principle is elaborately expounded by the essence of traditional Chinese culture, at the same time when the ideological and political education is proceeded, it will enhance the student's understanding of the traditional Chinese culture, and will arouse the students' interest in the process of constantly deep going.

"Interest in learning is a tendency for students to have a passion, chasing and longing for learning activities." Era is in development, this can not be violated, and the excellent traditional culture should be epochal, excellent traditional culture, in the process of ideological and political education, should continue to absorb the various nourishment from today's society to strengthen itself. Evaluate the affairs of today's society that students are interested in from a scientific and rational view and take advantages of them by a smooth transition in these things, to stimulate the enthusiasm of the students, at the same time, take them into the traditional Chinese culture.

Finally, maintain the teaching atmosphere, make moderate integration. It is said that school is the tower of ivory, without social's dirt, so the school should strive to maintain teaching atmosphere on campus, excellent teachers can certainly distinguish the dross from cultural invasions, promptly and resolutely correct the eliminate it to shape the ideal excellent traditional Chinese culture. In addition to the explanation of the lessons in classroom, the specific measures should also be taken to reflect the charm of traditional Chinese culture in the daily life of students. For example, sites like canteen and dormitory where students always live together should be decorated with traditional marks when holidays come. In school organize festival activities, abandon the idea of festivals equivalence to days-off, engrave the traditional Chinese culture into life, this is the form of ideological and political education should be. 


\section{Concluding remarks}

In fact, the fusion of Chinese excellent traditional culture with ideological and political education is not difficult. It is difficult to produce positive results. The current traditional culture is fading, but does not mean that it is lack of cultural charm. So, blunt integration should not be taken, it should be gradual, and start from life, take atmosphere infection and imperceptible influence, and the ideological and political education also come out from the classroom into the life of the students, in the field of life, because the excellent traditional Chinese culture is inclusive, and students as Chinese people have the sense of identity, the ideological and political education will naturally combined with traditional Chinese culture. The essence of culture is the pursuit of the goal of ideological and political education. Then with the appropriate correction from teachers, the excellent traditional Chinese culture will naturally integrate with ideological and political education, and in the process of integration the culture is strengthened, ideological and political education is sublimated, achieving a win-win situation.

\section{Acknowledgement}

This paper was supported by Scientific and Technological Planning Project of Beihua University (No.YB201622 and No.202116168).

\section{Reference}

[1] Feng Biao, the present situation of Chinese traditional culture and Its Countermeasures -- Based on the questionnaire survey of college students (J), China Electric Power Education, 2010 (33)

[2] Liu Shuxia, the Chinese traditional culture and ideological and political education integration of factual and ideal situation (J), Tangdu journal, 2011 (1)

[3] Li Liang, an analysis of the role of Chinese excellent traditional culture in Ideological and political education in Colleges and universities (J), Journal of Social Sciences of Jiamusi University, 2012 (4)

[4] Tang Xinfang, the investigation and analysis of the cognition of the traditional culture of the post-90s college students (J), Journal of Hubei Correspondence University, 2013 (3)

[5] Chen Shaoping, research on Chinese traditional culture education and ideological and political education in Colleges and universities (J), ideological education research, 2016 (6)

[6] A study on the current situation and Countermeasures of Chinese excellent traditional culture education of college students based on [6] Zhang Yanan -- a case study of the universities in Qing Dynasty (D), Qingdao University of Science \& Technology, 2016 